\title{
British Journal of Pharmacy
}

\author{
www.bjpharm.hud.ac.uk
}

Research Article

\section{Interprofessional Education: An Evaluation of a Joint Learning Workshop for Podiatry and Pharmacy Students}

\author{
Katie Greenwood,* Elizabeth Horncastle, John Stephenson
}

Department of Pharmacy, School of Applied Sciences, University of Huddersfield, United Kingdom

\begin{tabular}{|c|c|}
\hline A R T I C L E I N F O & A B S T R A C T \\
\hline $\begin{array}{l}\text { KEYWORDS: } \\
\text { Inter-professional education, } \\
\text { Collaboration, Podiatry } \\
\text { education, Pharmacy } \\
\text { education, Teaching and } \\
\text { learning }\end{array}$ & $\begin{array}{l}\text { "Interprofessional Education occurs when two or more professionals learn with, from and } \\
\text { about each other to improve collaboration and the quality of care" (CAIPE 2002). } \\
\text { Interprofessional education forms part of the Standards for the Initial Education } \\
\text { and Training of Pharmacists. Working with and understanding the role of another } \\
\text { profession has been shown to positively impact on the quality of care of the } \\
\text { patient. Following positive pharmacy student feedback from visits to podiatry } \\
\text { clinics an interprofessional learning workshop with case - based scenarios was } \\
\text { developed. These were based on patients with high risk medical conditions that } \\
\text { would impact on the work of both professions. Data from the feedback forms was } \\
\text { evaluated and analysed to determine whether the workshop increased knowledge } \\
\text { of the British National Formulary (BNF), the prescribing process and gave an } \\
\text { insight in to the role of other healthcare professionals. We discuss how the } \\
\text { student's learning has been enhanced by the contribution of another professional } \\
\text { group. The workshop was positively received. Students were observed working } \\
\text { together discussing the patients' conditions and issues relating to their care. This } \\
\text { initially revolved around the students' area of knowledge; however, as the session } \\
\text { progressed it became apparent that the students were learning with, from and } \\
\text { about each other for the benefit of patient care. }\end{array}$ \\
\hline
\end{tabular}

(c) Open Access 2016 - University of Huddersfield Press

\section{INTRODUCTION}

In the healthcare environment interprofessional collaboration is increasingly being recognised as being imperative to ensure high quality care which is responsive to the patient's needs (Ateah et al 2011).

Interprofessional education (IPE), forms part of the Standards for the Initial Education and Training of Pharmacists (GPhC 2011). Working with and understanding the roles of other healthcare professionals impacts on the quality of care of the patient. This is endorsed by The Health and Care
Professions Council in their Standards for Education. (HCPC 2009).

It has been recognised that IPE is a viable method of advancing effective team working. Different disciplines are able to contribute a range of professional knowledge and skills in a complimentary way to work towards a common goal. It has also been acknowledged that introducing professionals to interprofessional education early in their careers can help students be less competitive and more collaborative (Carlisle et al. 2004). Barr et al. (1999) have identified that IPE can reduce attitudinal barriers which can exist between 
difference disciplines due to misunderstanding of the other professionals' role. By participating in IPE, members of one profession discover what the other profession(s) 'bring to the table' and therefore develop an awareness of where it would be appropriate to involve them in a patient's care.

Developing the ability to effectively communicate with and work together with other members of the healthcare team is essential for the delivery of high quality, safe patient care and to avoid inadvertent patient harm. However, effective communication is often influenced by the situation or personalities involved. IPE has been observed to help develop the healthcare professional's communication skills within different situations. (Leonard et al. 2004) Stereotyping has been identified as a barrier to collaboration between healthcare professionals. The perception of individuals from one profession by those of another has been shown to affect the collaboration between the professions. Limited exposure of students during their educational training to other healthcare professionals can reinforce this stereotyping (Ateah et al 2011). IPE undertaken early in the training of healthcare professionals can therefore help students to become aware of the actual role of another profession.

Marcel D 'Eon (2004) in his 'Blueprint for Interprofessional Learning' discusses how cooperative learning in an interprofessional education environment must incorporate the five elements of best practice identified by Lewis et al in 2001 as: positive independence; face to face promotive interaction; individual accountability; social skills and group processing. Students should have a common goal when addressing the problem that they are presented with in order to optimise patient care.

Second year pharmacy students attend a University of Huddersfield podiatry clinic. These clinics are staffed by podiatry students under the supervision of academic staff who all hold professional qualifications. Pharmacy students are required to reflect on their visit to the podiatry clinic, these reflections form part of a portfolio of experiences and are assessed as part of course work requirements. Positive comments from the pharmacy students about the clinic visits led to the further development of the collaboration between the professions.

Our objectives in developing and delivering these sessions were to:

- expose pharmacy and podiatry students to interprofessional education at an early stage in their careers.

- develop knowledge, skills and attitudes in students to enhance patient centred care.

\section{MATERIALS AND METHODS}

An IPE intervention occurs when members of more than one health/social care profession learn interactively together, for the explicit purpose of improving interprofessional collaboration and/or the health/wellbeing of patients/clients. Interactive learning requires active learner participation and active exchange from learners from different professions" Reeves et al (2009 p3)

'Experiential learning' is learning that takes place as a result of an encounter with an experience that is planned by instructors within a course. (Kolb, 1984) Interactive learning requires active learning participation and the workshop setting enables active exchange between students from different professions (Reeves et al 2009). In addition the combination of learning in a clinic and a simulated activity helps students to transfer what had been learned in one situation to another that is not exactly the same (D 'Eon 2004). With this in mind a workshop was designed by members of both professions for both pharmacy and podiatry students to enhance the learning that had taken place in the clinics.

The sessions were led by both pharmacists and podiatrists to facilitate shared decision making and the development of respect for the contribution and values of each profession in patient care (Hall and Zierler 2015). Mixed professional groups of pharmacy students $(n=63)$ and podiatry students $(n=25)$ studied cases of patients with high risk medical conditions. The cases were developed by podiatrists and pharmacists by adapting information from real patients. The conditions chosen complications of diabetes (Fig. 1) and rheumatoid arthritis (Fig. 2), impact on the work of both professions and reflect the types of patients who attend the clinic. It has also been shown that using 
cases as the focus for the teaching "exposes students to problematic, real world situations and challenges them to apply course knowledge, analyse the issues and formulate workable solutions". (Nilson, 1998)

Groups were provided with details of two patients, their medical and social history and the medicines they were currently prescribed.

Case study 1 concerned Mr H, age 69, who had been referred to the High Risk Foot Clinic with a new episode of ulceration. This gentleman had a history of chronic foot ulcerations since being diagnosed with Charcot's Neuroarthropathy.

He had remained ulcer free for a duration of 6 months but when showering yesterday he had noticed, when he was drying himself, that his "right foot was weeping" (Fig. 1). He covered it with a sterile dry dressing as previously advised, and selfreferred into the clinic.

Whilst a history was being taken, $\mathrm{Mr} \mathrm{H}$ explained that he had been experiencing right leg pain for approximately one week. He suffers from painful diabetic neuropathy but complained that the pain was more severe, often waking him at night.

His medical history was:

Type 2 DM (2005) last HbA1c was $108 \mathrm{~mm} / \mathrm{mol}$ Painful Peripheral Neuropathy (2005)

Charcot's Neuroarthropathy (2010)

Hyperlipidaemia

Hypertension Recent BP 150/90

Diabetic Retinopathy

History of chronic diabetic foot ulcers

Depression

History of M.R.S.A (2007)

His current medication was

Metformin 500mg TDS

Gliclazide 80mg OD

Simvastatin 20mg OD

Atenolol 50mg OD

Aspirin 75mg OD

Amitriptyline Hydrochloride 75mg nocte

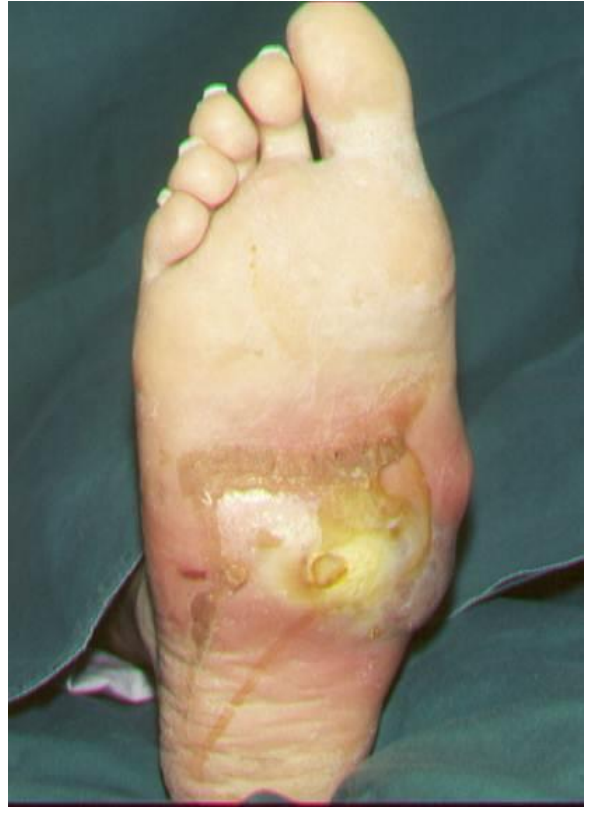

Fig. 1. Case Study 1- diabetic foot

Case study 2 concerned Mrs G, age 75, who had been referred by her district nurse to the High Risk Foot Clinic with a non-healing ulceration. (Fig. 2).This lady had a history of chronic foot ulceration. The right $4^{\text {th }}$ distal interphalangeal joint (DIPJ) and $5^{\text {th }}$ proximal interphalangeal joint (PIPJ) ulcerated 6 months ago and had failed to respond to treatment. The lesion was extremely painful.

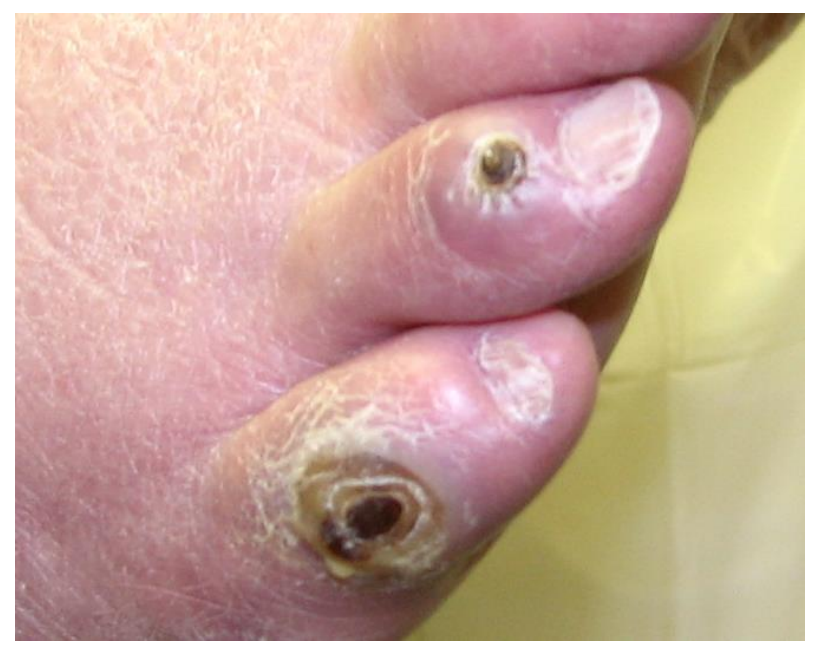

Fig. 2. Case Study 2- Rheumatoid arthritis

Mrs G also suffers from bilateral leg pain, particularly at night. The pain has increased in frequency and intensity to the extent it is affecting her sleep; she is often forced to hang her legs over the side of the bed to gain some relief. Mrs G also 
complains of a dry cough and swollen ankles during the consultation.

Her medical history was:

Rheumatoid Arthritis (1995)

Peripheral Vascular Disease (2010)

Hyperlipidaemia (2000)

Hypertension (2000)

Iron Deficiency Anaemia (2000)

Right Angiogram (2011)

Right Femoral artery occlusion (2011)

Right Transluminal Femoral Angioplasty (2011)

Right 2nd toe amputation (2012)

Her current medication was:

Co-codamol 30/500 QDS

Methotrexate $20 \mathrm{mg}$ per week

Simvastatin 40mg OD

Ramipril 5mg OD

Aspirin 75mg OD

Ferrous sulfate 200mg TDS

Amlodipine 5mg OD

The medication was presented either as a mock repeat slip from a prescription (Case study 1) or a bag of medicines; empty boxes which were labelled as though they were real (Case study 2). Information relating to the patients' medical histories and current test results was also available. Details of the cases were available to all students in the week before the workshop on the University Virtual Learning Environment (VLE).

Immediately after the workshop a feedback form was distributed to the students. This was used to collect data which was thematically evaluated and analysed.

\section{RESULTS AND DISCUSSION}

Responses were received from 98 participants. Of respondents who stated their profession, 25 were podiatry students $(28.4 \%)$ and 63 were pharmacy students $(71.6 \%)$. Ten students did not state their profession.

Respondents were asked a total of 9 Likert-style items; with each item allowing 6 options from Strongly Disagree (scoring 1 point) to Strongly Agree (scoring 6 points). The wording of the questions was such that more favourable responses were given higher scores. Responses to a number of open-ended questions were also elicited.

An exploratory correlation analysis revealed certain groups of questions to be correlated with each other. Substantive correlations, most of which were statistically significant, were observed between scores obtained on the following statements:

- This workshop has given me an insight into the role of another professional group

- I believe that individuals in my profession must depend on the work of people in other professions

- My learning from this workshop has been enhanced by the contribution of another professional group

- I believe that this experience of shared learning will help me become a more effective member of a health care team

- I believe that this experience of shared learning will increase my ability to understand clinical problems

- I believe that this experience of shared learning will improve my professional relationships after qualification

- The 9 questionnaire items could be effectively reduced to 3 discrete outcomes, (representing appreciation of interprofessional education, knowledge gain and commonality of skills) over which pharmacy and podiatry students could be compared.

A substantive correlation, which was statistically significant, was observed between scores obtained on the following statements:

- This workshop has increased my knowledge of the $B N F$

- This workshop has increased my understanding of the prescribing process

The final statement (below) was not substantively correlated with other statements.

- This workshop has demonstrated that my profession shares common skills and attitudes with podiatrists or pharmacists [stated profession depended on students' own profession] 
As a further exploratory procedure, a factor analysis conducted on the data revealed in three factors being extracted, which together accounted for $74 \%$ of model variance; with the items comprising each factor co-incident with the above groups. Outcome 1 may be considered to be a measure of appreciation of interprofessional education (IPE). Outcome 2 may be considered to be a measure of knowledge gain (Knowledge). Outcome 3 may be considered to be a measure of commonality of skills (Skills). Reliability analysis confirmed that each set, and the items comprising it, exhibited good reliability.

Hence three outcomes were considered to be represented by the items and three outcome variables, representing summed scores of all individual items within the outcome, were created. A descriptive summary of the entire sample, and of the sample partitioned by profession, is given in Table 1 .

Scores on the IPE Outcome (comprising 6 items) could range from 6 to 36; scores on the Knowledge Outcome (comprising 2 items) could range from 2 to 12; and scores on the Skills Outcome (comprising 1 item) could range from 1 to 6 . Hence strongly positive responses were recorded over the entire sample; with pharmacy students responding slightly more positively to the IPE and Skills outcomes; and podiatry students responding slightly more positively to the Knowledge outcome.

The 1.66 point difference in favour of podiatrists with respect to the Knowledge outcome was statistically significant $(p=0.005 ; 95 \%$ confidence interval for difference: 0.529 to 2.875). For three outcomes, significance was considered to be indicated by $1.67 \%$ $(5 \% / 3)$ by the application of a Bonferroni correction. Differences between professions on other outcomes were not considered to be significant under the application of this correction.

Further data analysis was undertaken on the assumption that the data could be approximated to interval-level. Analysis of correlations between outcome measures revealed the IPE outcome to be significantly correlated with both the knowledge outcome $(r=0.327, p=0.002)$ and the Skills outcome $(r=0.691, p<0.001)$; the Skills and Knowledge outcomes were not correlated Hence a multivariate analysis was undertaken on all outcome data jointly. In both cases, profession was the sole grouping variable. The multivariate analysis revealed that profession was significantly associated with a linear combination of the outcomes (Wilk's lambda $=0.820 ; \mathrm{F}_{3,76}=5.55$; $\mathrm{p}=0.002$ ). Follow-up univariate analyses revealed significant differences between groups on the Knowledge outcome $\left(\mathrm{F}_{1,78}=8.08 ; \mathrm{p}=0.006\right)$ but that group differences on the IPE outcome were substantive, but not significant $\left(\mathrm{F}_{1,78}=2.521 ; \mathrm{p}=0.117\right)$; and group differences on Skills outcome were also substantive, but not significant $\left(\mathrm{F}_{1,78}=3.26 ; \mathrm{p}=0.075\right)$.

Table 1 . Summary of the data analysis.

\begin{tabular}{|c|c|c|c|c|}
\hline \multirow[t]{2}{*}{ Outcome } & \multicolumn{3}{|c|}{ Mean (SD) } & \multirow[t]{2}{*}{$p$-value } \\
\hline & $\begin{array}{l}\text { Podiatry } \\
\text { students }\end{array}$ & $\begin{array}{c}\text { Pharmacy } \\
\text { students }\end{array}$ & $\begin{array}{c}\text { All } \\
\text { students }\end{array}$ & \\
\hline $\begin{array}{l}\text { IPL } \\
6 \text { questions } \\
\text { (36 points) }\end{array}$ & $\begin{array}{c}30.3 \\
(6.24)\end{array}$ & $\begin{array}{c}32.1 \\
(3.28)\end{array}$ & $\begin{array}{c}31.6 \\
(4.36)\end{array}$ & 0.088 \\
\hline $\begin{array}{l}\text { Knowledge } \\
2 \text { questions } \\
\text { (12 points) }\end{array}$ & $\begin{array}{c}8.17 \\
(2.21)\end{array}$ & $\begin{array}{c}6.52 \\
(2.33)\end{array}$ & $\begin{array}{c}6.99 \\
(2.41)\end{array}$ & 0.005 \\
\hline $\begin{array}{l}\text { Skills } \\
1 \text { question } \\
\text { (6 points) }\end{array}$ & $\begin{array}{c}4.92 \\
(1.08)\end{array}$ & $\begin{array}{l}5.32 \\
(0.74)\end{array}$ & $\begin{array}{c}5.21 \\
(0.87)\end{array}$ & 0.049 \\
\hline
\end{tabular}

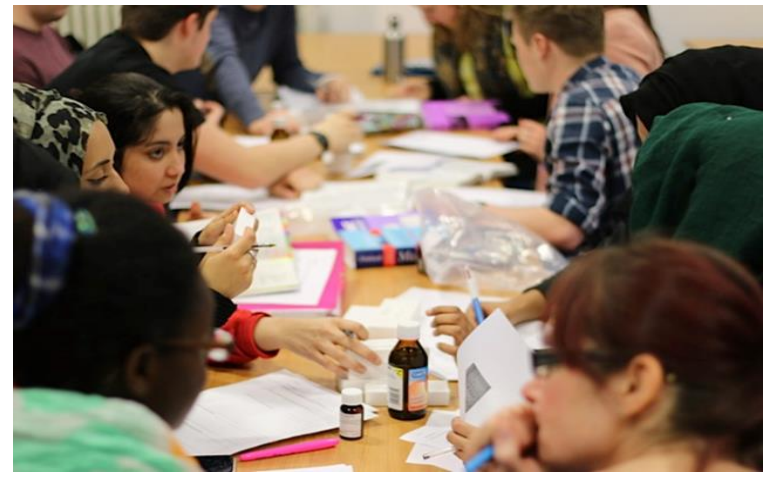

Fig.3. Students examining the medicines provided in Case study 2Rheumatoid Arthritis

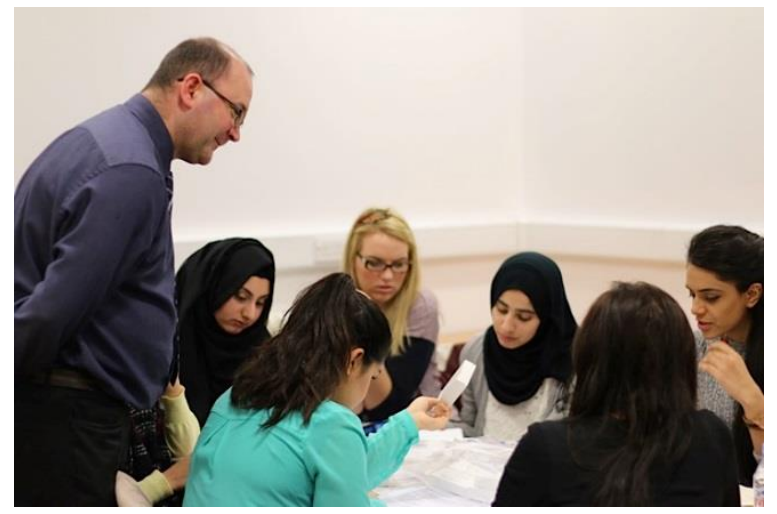

Fig. 4. Discussing Case Study 1-Diabetic Foot. 
Hence in summary, it may be stated that:

- The overall impression of the workshop was very positive across the full cohort.

- Pharmacy students were more positive than podiatry students in the appreciation of interprofessional education and commonality of skills outcomes

- Podiatry students were significantly more positive than pharmacy students in the knowledge gain outcome $(\mathrm{p}=0.005$ on a difference of 1.66 points).

- No significance was observed in those outcomes in which pharmacy students were more positive.

\section{CONCLUSIONS}

The evaluation demonstrated the development of the students' skills, knowledge and attitudes. Pharmacy students were more positive in the appreciation of interprofessional education and commonality of skills outcomes; whereas podiatry students were more positive in the knowledge gain outcome.

The workshop was positively received by participants. Students were observed working together discussing the patients' condition and issues relating to their care. This initially revolved around the students' area of knowledge; however, as the session progressed it became apparent that the students were learning with, from and about each other for the benefit of patient care.

\section{ACKNOWLEDGEMENTS}

We would like to thank our podiatry colleagues Matt Rothwell and Jim Pickard for their help in creating the scenarios and facilitating the sessions. We are also grateful to our pharmacy colleagues Andy Adams and Iqbal Mohammed for supporting us in the delivery of the sessions. Many thanks to the students for embracing the concept of interprofessional education.

\section{REFERENCES}

Ateah,C.A., Snow, W, Wener,P. MacDonald,L. Metge,C. Davis, P. Ludwig, S. and Anderson,J. (2011). Stereotyping as a barrier to collaboration: Does inter-professional education make a difference? Nurse Education Today 31 208-213

Barr, H., Hammick, M., Koppel, I and Reeves, S. (1999). Evaluating IPE: two systematic reviews for health and social care. British Education Research Journal, 25, p 533544

CAIPE (2002). Centre for the advancement of Interprofessional Education http:/ / caipe.org.uk/resources/defining-ipe, last accessed 20/6/16.

D 'Eon, M. (2004). A Blueprint for Inter Professional Learning, Medical Teacher. 2062.7, 604-609, DOI: $10.1080 / 01421590400004924$

GPhC (2011). General Pharmaceutical Council. http://www.pharmacyregulation.org/sites/default/file s/GPhC_Future_Pharmacists.pdf, Last accessed 20/6/16

Hall, L.W. and Zierler, B.K. (2015). Inter-professional Education and Practice Guide No.1; Developing Faculty to Effectively Facilitate Interprofessional Education. Journal of Interprofessional Care; 29(1):3-7

HCPC (2009). Health and Care Professions Council. Standards of Educations and Training. London.

Kolb, D.A. (1984). Experiential Learning Experience as the Source of Learning and Development. Englewood Cliffs, NJ, Prentice Hall

Leonard M, Graham, S, Bonacum, D (2004). The human factor: the critical importance of effective teamwork and communication in providing safe care.

Lewis, R.E.Tucker, R. Tsao, Canaan,E. Bryant, P. Talbot P, King, D and Flythe M(2001). Improving interdiscIPEinary team process: a practical approach to team development, Journal of Allied Health , 9, pp. 89-95.

Nilson, L.B. (1998). Teaching at its Best: a Research - Based Resource for College Instructors. Bolton, MA, Anker Publishing.

Reeves, S, Zwarenstein, M., Barr, H., Freeth, D., Hammick $\mathrm{M}$ and Koppel, I. (2008). Interprofessional Education: effects on professional practice and healthcare outcomes (review). Cochrane Database Syst Rev.1, CD002213. 